\title{
Seismic behavior of three dimensional concrete rectangular containers including sloshing effects
}

\author{
H. Mirzabozorg*1, M.A. Hariri-Ardebili ${ }^{2}$ and R. Nateghi A. ${ }^{3}$ \\ ${ }^{1}$ Department of Civil Engineering, K. N. Toosi University of Technology, Tehran, Iran \\ ${ }^{2}$ Department of Civil, Environmental and Architectural Engineering, University of Colorado, Boulder, USA \\ ${ }^{3}$ Department of Civil Engineering, K. N. Toosi University of Technology, Tehran, Iran
}

(Received December 10, 2011, Revised February 28, 2012, Accepted March 12, 2012)

\begin{abstract}
In the present paper, the three-dimensional model of a typical rectangular concrete tank is excited using an artificial and a natural three components earthquake ground motion and the staggered displacement method is utilized for solving the coupled problem of the tank-contained liquid system in time domain. In the proposed method, surface sloshing of the liquid is taken into account in addition to the impulsive term and the appropriate damping values are applied on both of them. The resulted responses are compared with those obtained from the ABAQUS finite element software. It is found that the convective term affects responses extensively and must be considered in seismic design/safety assessment of storage tanks. In addition, the utilized method for solving the coupled problem is stable during the conducted general dynamic analyses and is able to capture the expected phenomena.
\end{abstract}

Keywords: tank-contained liquid interaction; staggered displacement method; surface sloshing; multicomponent ground motion; rectangular concrete tank

\section{Introduction}

Nowadays, liquid storage tanks play an important role as one of the components in the life line and are widely used in order to containing liquids and compressed gases and therefore, their failure can lead to extensive damage. Tanks maybe divided into various categories based on their material, shape, support type and etc. While steel and concrete remain one of the most common choices for tanks, using GRP; thermoplastic; polyethylene and fibreglass tanks increases because they offer lower build costs and greater resistance, especially for storing chemical materials. Generally, the two types of configuration used extensively for tanks are cylindrical and rectangular shapes, which can be underground; ground supported or elevated. Several researchers have studied on the liquid storage tanks behaviours in static and dynamic conditions considering simplified assumptions. Most of them studied cylindrical tanks while less attention has been paid on rectangular ones.

In the field of ground supported storage tanks, Hamdan (2000) investigated the accuracy of design guidelines for the seismic response of cylindrical steel liquid storage tanks. The dynamic responses of cylindrical steel tanks in various conditions were studied by Nourali-Ahari et al. (2009),

\footnotetext{
* Corresponding author, Assistant Professor, E-mail: Mirzabozorg@kntu.ac.ir
} 
Nachtigall et al. (2003), Bayraktar et al. (2010) and Berahman and Behnamfar (2010). Kianoush and Ghaemmaghami (2011) studied the effects of earthquake frequency content on the seismic behaviour of concrete rectangular tanks. They used different models of shallow and tall tanks on various types of soils and concluded that the response of tank-fluid-soil system is highly affected by the frequency contents of earthquakes. Chen and Kianoush (2009) proposed a simplified method using the generalized SDOF system for seismic analysing and design of concrete tanks. Kianoush and Chen (2006) studied the effect of vertical component of the ground motions on the dynamic response of a rectangular concrete tank. Livaoglu (2008) studied the seismic behaviour of rectangular tanks considering the foundation interaction effects in frequency domain. Ming and Duan (2010) introduced a new technique for numerical simulation of sloshing in the fluid-structure interaction problems based on the unstructured grids. Ghaemian et al. (2005) and Kianoush et al. (2006) investigated 3D dynamic analysis of liquid storage tanks. Shrimali and Jangid (2003) studied the earthquake response of the isolated elevated liquid steel tanks in which lumped mass approach was used for sloshing, impulsive and rigid part of the contained liquid. In addition, Seismic responses of the elevated tanks were studied by Moslemi et al. (2011), Livaoglu and Dogangun (2007) and, Dutta et al. (2000). Sweedan (2009) was proposed an equivalent mechanical model for investigating the effect of vertical component of the ground motion on the combined tanks using a coupled boundaryfinite element formulation. Estekanchi and Alembagheri (2012) used the endurance time analysis method for seismic assessment of cylindrical tanks. In this technique, they used intensifying acceleration functions in order to estimate the response of the system in various performance levels. Virella et al. (2006) investigated buckling of anchored steel tanks subjected to the horizontal components of the ground motions.

On the other hand, sloshing of the liquid during dynamic loads has important effects on the responses of the tanks due to applying the pertinent hydrodynamic pressures at higher levels of surrounding walls. Several researchers studied the linear and nonlinear modelling of fluid surface sloshing using various numerical techniques. Celebi and Akyildiz (2002) studied the nonlinear sloshing effects on a rectangular moving tank using the finite difference method. This technique was used by Hernández-Barrios (2007) for seismic analysing the cylindrical tanks and $\mathrm{Wu}$ and Chen (2009) used time-independent version of the technique for 3D assessment of tanks. Huang et al. (2010) used the time-domain Green function based on the boundary element method to simulate tank-sloshing problems. Also, they verified their numerical model with experimental tests. Cho and Lee (2004) introduced a velocity-potential-based nonlinear finite element method for simulation of occurring the large amplitude liquid sloshing in a two-dimensional baffled tank subject to the horizontal forced excitation. Frandsen (2004) introduced a fully non-linear finite difference model using in-viscid flow equations. Nasar et al. (2008) investigated experimentally the sloshing of the liquid in partially filled tanks mounted on a barge exposed to regular beam waves. They also studied the effects of wave excitation frequency and wave height on the sloshing oscillation as well as on the response of the barge. Firouz-Abadi et al. (2009) introduced application of a reduced order modelling technique for investigation of liquid sloshing in 3D tanks using boundary element formulation. Also Firouz-Abadi et al. (2011) used a modal approach for second-order analysing the sloshing utilizing boundary element method.

In the present paper, the staggered displacement method is used for solving the coupled tankcontained liquid problem in time domain considering surface sloshing effects. The accuracy and applicability of the provided program in solving the coupled problems has been considered in several works like as Mirzabozorg et al. (2003), Mirzabozorg and Ghaemian (2005) and Mirzabozorg 
et al. (2009). The main advantafge of the used method is utilizing eulerian approach in formulating the liquid domain which leads to simpler boundary conditions and less degrees of freedom in the liquid domain. In addition, the proposed formulation can be solved using standard solvers due to symmetric matrices appearing in the structure and liquid dynamic equation of motions. The provided finite element program is able to take into account both the convective and impulsive components of the contained liquid. A 3D coupled system of liquid-tank finite element model is provided and excited using artificial and real ground motions records in horizontal and vertical directions and the results are compared with those obtained from the commercial software, which uses different approach for solving the coupled problem.

\section{Governing equation in liquid domain}

The governing equation of motion in the liquid contained in a tank is given as

$$
\nabla^{2} p=0
$$

where, $p$ is the hydrodynamic pressure developed within the liquid domain. In order to solve the above equation using the finite element technique, a set of appropriate boundary conditions are required as discussed in the following sections.

\subsection{Boundary condition at liquid-tank interface}

On the interface of liquid and concrete tank, there is no flow. The appropriate boundary condition on the interface is given as

$$
\frac{\partial p}{\partial n}=-\rho a_{n}^{s}
$$

in which, $n$ and $a_{n}{ }^{s}$ are outwardly normal direction to the tank wall and the normal acceleration applied on the liquid on the interface, respectively and $\rho$ is the liquid density.

\subsection{Boundary condition at free surface}

Considering small amplitude gravity waves on the free surface of the liquid, the resulting boundary condition is given as

$$
\frac{1}{g} \frac{\partial^{2} p}{\partial t^{2}}+\frac{\partial p}{\partial z}=0
$$

in which, $z$ identifies the vertical direction and $g$ is the acceleration gravity.

\subsection{Discretised equation of liquid domain}

Using Galerkin's technique, the discretised finite element governing equation of motion in liquid domain is given as 


$$
[G]\{\ddot{P}\}+\left[C_{f}\right]\{\dot{P}\}+\left[K_{f}\right]\{P\}=\{F\}
$$

in which

$$
\begin{gathered}
G_{i j}^{e}=\frac{1}{g_{A_{e}}} N_{i} N_{j} d A \\
H_{i j}^{e}=\int_{V_{e}}\left(\frac{\partial N_{i}}{\partial x} \frac{\partial N_{j}}{\partial x}+\frac{\partial N_{i}}{\partial y} \frac{\partial N_{j}}{\partial y}+\frac{\partial N_{i}}{\partial z} \frac{\partial N_{j}}{\partial z}\right) d v \\
\{F\}=\left\{F_{i}\right\}-\rho[Q]^{T}\left(\{\ddot{U}\}+\left\{\ddot{U}_{g}\right\}\right) \\
F_{i}^{e}=\int_{A_{e}} N_{i} \frac{\partial P}{\partial n} d A
\end{gathered}
$$

where $N_{i},\{\ddot{U}\},\left\{\ddot{U}_{g}\right\},[Q]$ and $\left[C_{f}\right]$ are shape function of the $i^{\text {th }}$ node in the liquid element, acceleration vector of nodes in the structure domain, ground acceleration vector applied on the system, coupling matrix and finally, damping matrix of the liquid domain, respectively.

\subsection{Coupling matrix}

The coupling matrix, $[Q]$ transfers pressures applied on the liquid-wall interface as nodal forces to the tank walls. In the present paper, this matrix is generated using proportional lumping method. For 8-node interface elements with $x, y$ and $z$ translational DOF at each node on the face of the tank wall and the corresponding four node interface elements with pressure DOF at each node attached to the liquid element, the coupling matrix is given as (Eq. (6))

in which

$$
[Q]=\omega \int_{-1-1}^{1} \int_{1}^{1}\left[\begin{array}{ccc}
\alpha_{1} N_{1}^{s} N_{1}^{s} N_{1}^{f} & & \alpha_{1} N_{1}^{s} N_{1}^{s} N_{4}^{f} \\
\beta_{1} N_{1}^{s} N_{1}^{s} N_{1}^{f} & \ldots & \beta_{1} N_{1}^{s} N_{1}^{s} N_{4}^{f} \\
\gamma_{1} N_{1}^{s} N_{1}^{s} N_{1}^{f} & & \gamma_{1} N_{1}^{s} N_{1}^{s} N_{4}^{f} \\
\vdots & \ddots & \vdots \\
\alpha_{8} N_{8}^{s} N_{8}^{s} N_{1}^{f} & & \alpha_{8} N_{8}^{s} N_{8}^{s} N_{4}^{f} \\
\beta_{8} N_{8}^{s} N_{8}^{s} N_{1}^{f} & \ldots & \beta_{8} N_{8}^{s} N_{8}^{s} N_{4}^{f} \\
\gamma_{8} N_{8}^{s} N_{8}^{s} N_{1}^{f} & & \gamma_{8} N_{8}^{s} N_{8}^{s} N_{4}^{f}
\end{array}\right]\left\|t_{\xi} \times t_{\eta}\right\| d \xi d \eta
$$

$$
\begin{gathered}
\vec{t}_{\xi}=\left\{\frac{\partial x}{\partial \xi}, \frac{\partial y}{\partial \xi}, \frac{\partial z}{\partial \xi}\right\}^{T} \\
\overrightarrow{t_{\eta}}=\left\{\frac{\partial x}{\partial \eta}, \frac{\partial y}{\partial \eta}, \frac{\partial z}{\partial \eta}\right\}^{T} \\
\omega=\frac{A}{\sum_{i=1}^{8} \int_{A_{e}} N_{i}^{s} N_{i}^{s}\left\|t_{\xi} \times t_{\eta}\right\| d \xi d \eta}
\end{gathered}
$$




$$
A=\int_{A_{e}}\left\|t_{\xi} \times t_{\eta}\right\| d \xi d \eta
$$

where, $N^{f}$ and $N^{s}$ are the shape functions in the liquid and structure domains, respectively.

\subsection{Damping within the liquid domain}

The damping matrix within the liquid domain includes two terms, which are originated from impulsive and convective terms as following:

$$
\left[C_{f}\right]=a[G]+b\left[K_{f}\right]
$$

in which $a$ and $b$ are computed based on Rayleigh damping. However, $a$ is computed based on the fundamental vibration frequency of the free surface waves and $b$ is computed based on the fundamental frequency of the impulsive component.

\section{Coupled equations of the tank and liquid}

The tank-liquid problem is a classical coupled problem, which contains two second-order differential equations. The equations of the tank and the liquid are written in the following form

$$
\begin{gathered}
{[M]\{\ddot{U}\}+[C]\{\dot{U}\}+[K]\{U\}=\left\{f_{1}\right\}-[M]\left\{\ddot{U}_{g}\right\}+[Q]\{P\}=\left\{F_{1}\right\}+[Q]\{P\}} \\
{[G]\{\ddot{P}\}+\left[C_{f}\right]\{\dot{P}\}+\left[K_{f}\right]\{P\}=\{F\}-\rho[Q]^{T}\left(\{\ddot{U}\}+\left\{\ddot{U}_{g}\right\}\right)=\left\{F_{2}\right\}-\rho[Q]^{T}\{\ddot{U}\}}
\end{gathered}
$$

\subsection{Numerical solution of the coupled equations}

In the present paper, direct integration scheme is used to find the displacement and hydrodynamic pressure at the end of the time increment $i+1$ given the displacement and hydrodynamic pressure at time $i$. The $\alpha$-method is used for discretization of both equations (implicit-implicit method). In this method $\{U\}_{i+1},\{U\}_{i+1},\{P\}_{i+1}$ and $\{P\}_{i+1}$ can be written as follows

$$
\begin{aligned}
& \{\dot{U}\}_{i+1}=\{\dot{U}\}_{i+1}^{P}+\gamma \Delta t\{\ddot{U}\}_{i+1} \\
& \{\dot{U}\}_{i+1}^{P}=\{\dot{U}\}_{i}+(1-\gamma) \Delta t\{\ddot{U}\}_{i} \\
& \{U\}_{i+1}=\{U\}_{i+1}^{P}+\beta \Delta t^{2}\{\ddot{U}\}_{i+1} \\
& \{U\}_{i+1}^{P}=\{U\}_{i}+\Delta t\{\dot{U}\}_{i}+(1-\beta) \Delta t^{2}\{\ddot{U}\}_{i} \\
& \{\dot{P}\}_{i+1}=\{\dot{P}\}_{i+1}^{P}+\gamma \Delta t\{\ddot{P}\}_{i+1} \\
& \{\dot{P}\}_{i+1}^{P}=\{\dot{P}\}_{i}+(1-\gamma) \Delta t\{\ddot{P}\}_{i} \\
& \{P\}_{i+1}=\{P\}_{i+1}^{P}+\beta \Delta t^{2}\{\ddot{P}\}_{i+1}
\end{aligned}
$$




$$
\{P\}_{i+1}^{P}=\{P\}_{i}+\Delta t\{\dot{P}\}_{i}+(1-\beta) \Delta t^{2}\{\ddot{P}\}_{i}
$$

where, $\gamma$ and $\beta$ are the integration parameters. The governing field equations at time $i+1$ can be written as follows

$$
\begin{gathered}
{[M]\{\ddot{U}\}_{i+1}+[C]\{\dot{U}\}_{i+1}+(1+\alpha)[K]\{U\}_{i+1}=\left\{F_{1}\right\}_{i+1}+[Q]\{P\}_{i+1}+\alpha[K]\{U\}_{i}} \\
{[G]\{\ddot{P}\}_{i+1}+\left[C^{\prime}\right]\{\dot{P}\}_{i+1}+(1+\alpha)\left[K^{\prime}\right]\{P\}_{i+1}=\left\{F_{2}\right\}_{i+1}-\rho[Q]^{T}\{\ddot{U}\}_{i+1}+\alpha\left[K^{\prime}\right]\{P\}_{i}}
\end{gathered}
$$

These two coupled field equations can be solved using the staggered displacement method, in which Eq. (15) is approximated as follows

$$
[M]\{\ddot{U}\}_{i+1}^{*}=\left\{F_{1}\right\}_{i+1}+[Q]\{P\}_{i+1}^{p}-[C]\{\dot{U}\}_{i+1}^{p}-(1+\alpha)[K]\{U\}_{i+1}^{p}+\alpha[K]\{U\}_{i}
$$

Combining Eqs. (15) and (17) gives

$$
[M]\{\ddot{U}\}_{i+1}=[M]\{\ddot{U}\}_{i+1}^{*}+\beta \Delta t^{2}[Q]\{\ddot{P}\}_{i+1}-\gamma \Delta t[C]\{\ddot{U}\}_{i+1}-(1+\alpha) \beta \Delta t^{2}[K]\{\ddot{U}\}_{i+1}
$$

By neglecting higher order terms, Eq. (18) is reduced to

$$
[M]\{\ddot{U}\}_{i+1}=[M]\{\ddot{U}\}_{i+1}^{*}+\beta \Delta t^{2}[Q]\{\ddot{P}\}_{i+1}
$$

Substituting Eq. (19) into Eq. (16), then

$$
\begin{gathered}
\left([G]+\rho \beta \Delta t^{2}[Q]^{T}[M]^{-1}[Q]\right)\{\ddot{P}\}_{i+1}+\left[C^{\prime}\right]\{\dot{P}\}_{i+1}+(1+\alpha)\left[K^{\prime}\right]\{P\}_{i+1}= \\
\left\{F_{2}\right\}_{i+1}-\rho[Q]^{T}\{\ddot{U}\}_{i+1}^{*}+\alpha\left[K^{\prime}\right]\{P\}_{i}
\end{gathered}
$$

The right hand side terms are known, thus, $\{P\}_{i+1}$ is obtained. In order to correct the approximation made in Eq. (19), $\{P\}_{i+1}$ is substituted in Eq. (15) to calculate $\{U\}_{i+1}$ and its derivatives. The procedure of the staggered displacement method is summarized as shown in Fig. 1.

This method is unconditionally stable for the linear coupled equations while for the non-linear systems; the numerical solution stability depends on the length of the time steps and the introduced numerical damping.

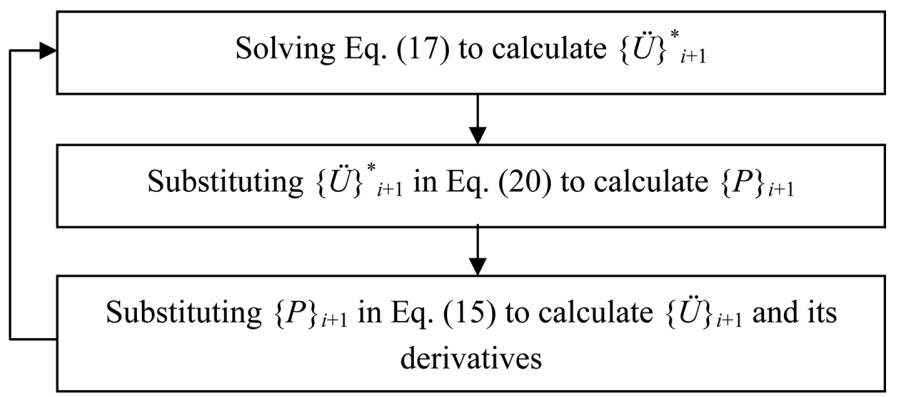

Fig. 1 The staggered displacement method procedure 


\section{Finite element implementation of the proposed model}

The 20-node iso-parametric element is used in finite element modelling of the tank walls. The stiffness matrix and all of the other related components are based on $3 \times 3 \times 3$ Gaussian integration points in the structure domain. The liquid domain is modelled using 8-node iso-parametric fluid elements with $2 \times 2 \times 2$ Gaussian integration points. For the interface elements between the structure and the liquid, $3 \times 3$ Gaussian integration points are used and for the other surface elements on the boundary of the liquid, $2 \times 2$ Gaussian integration points are employed. Fig. 2 represents ordering of Gaussian points within solid elements, fluid elements and solid-fluid interface elements.

\subsection{Numerical model}

3D finite element model of a tank and the contained liquid are provided as case study. The general view of the considered tank-liquid system and also the corresponding discretised finite element model are shown in Figs. 3 and 4. The finite element model of the system includes 38420 node solid elements for modelling the tank walls and 1000 8-node fluid elements for modelling the liquid domain. The dimensions and properties of the considered coupled system are summarized in Table 1.

\subsection{Loading}

The applied loads on the system are the tank self-weight, hydrostatic pressure and dynamic loads.

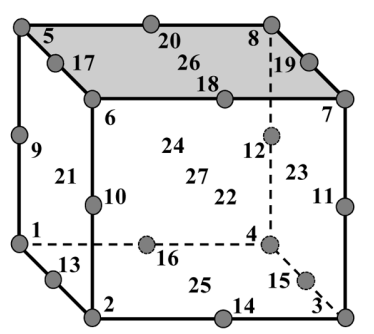

(a)

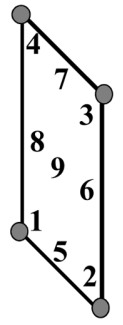

(b)

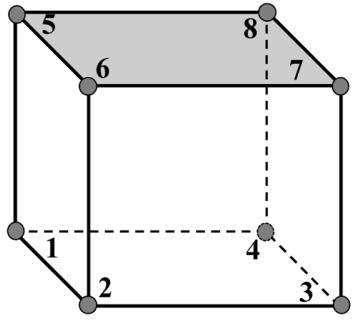

(c)

Fig. 2 Ordering of Gaussian points within (a) 20-Node solid elements, (b) 4-node solid-fluid interface elements and (c) 8-node fluid elements

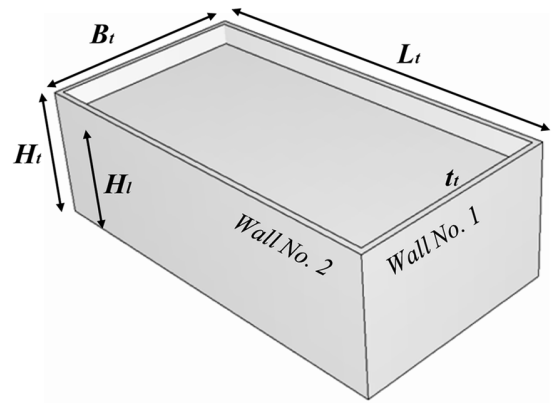

Fig. 3 General view and characteristics of the modelled 3D tank 


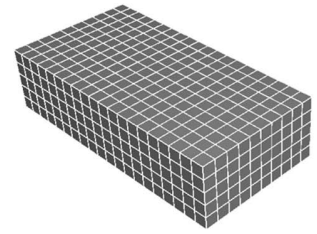

(a)

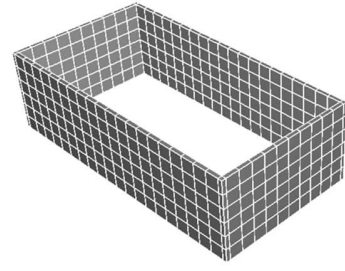

(b)

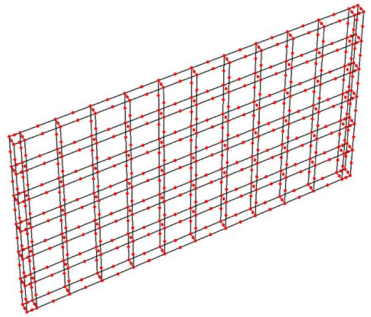

(c)

Fig. 4 Finite element discretization of the (a) liquid domain, (b) tank domain and (c) detailed mesh of wall No. 1

Table 1. Dimensions and properties of tank and liquid domain

\begin{tabular}{ll}
\hline \hline \multicolumn{1}{c}{ Tank domain } & \multicolumn{1}{c}{ Liquid domain } \\
\hline Mass density $\rho_{t}=25000 \mathrm{~N} / \mathrm{m}^{3}$ & Mass density $\rho_{1}=9807 \mathrm{~N} / \mathrm{m}^{3}$ \\
Modulus of elasticity $E_{t}=27.39 * 10^{9} \mathrm{~N} / \mathrm{m}^{2}$ & Sound velocity $C=1438 \mathrm{~m} / \mathrm{s}$ \\
Poisson's ratio $v=0.17$ & Liquid height $H_{1}=5.0 \mathrm{~m}$ \\
Tank height $H_{t}=6.0 \mathrm{~m}$ & \\
Tank length $L_{t}=20.6 \mathrm{~m}$ & \\
Tank width $B_{t}=10.6 \mathrm{~m}$ & \\
Tank thickness $t_{t}=0.30 \mathrm{~m}$ & \\
\hline
\end{tabular}

Two different scenarios are considered for dynamic analysis of the coupled system; artificial dynamic load; and a real earthquake ground motion record. In the first case, a simple intensifying time stepped load is used in which its amplitude and phase change every 5s (as shown in Fig. 5). For the second case, the horizontal and vertical components of the earthquake recorded for El Centro 1940 are used so that the peak ground acceleration (PGA) is $0.348 \mathrm{~g}$ in horizontal direction. Both two horizontal and vertical components are scaled in such a way that the PGA in the main horizontal component is $0.4 \mathrm{~g}$ (for comparison with the artificial dynamic load). The ground accelerations for the horizontal and vertical components are shown in Fig. 6. The responses of the system under real ground motion record are computed for each of the horizontal and vertical components and also due to combination of the three components. It's worthy to note that for the dynamic analysis of the system using the real ground motion only first 10 s of the selected record is used.

It's noteworthy that the time integration step is $0.005 \mathrm{~s}$ in all the conducted dynamic analyses. The

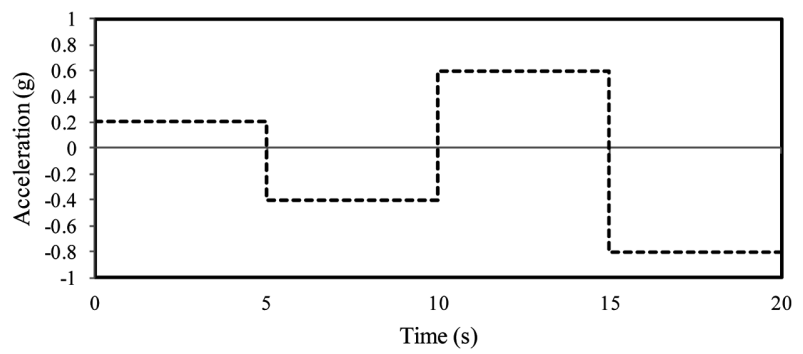

Fig. 5 Acceleration time-history of the artificial dynamic load 


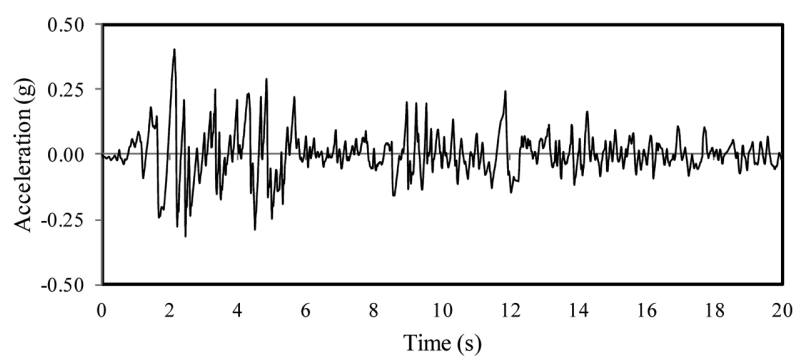

(a)

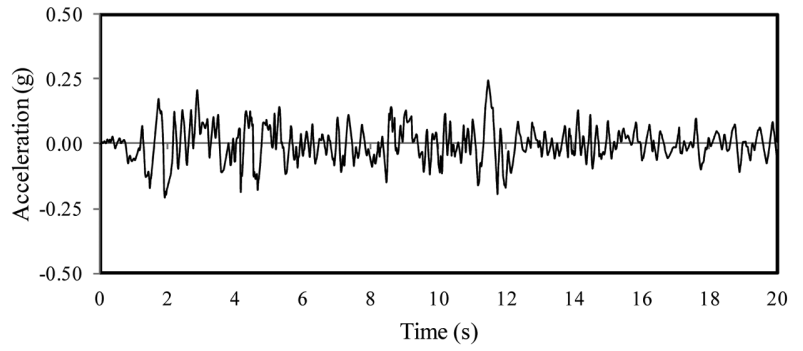

(b)

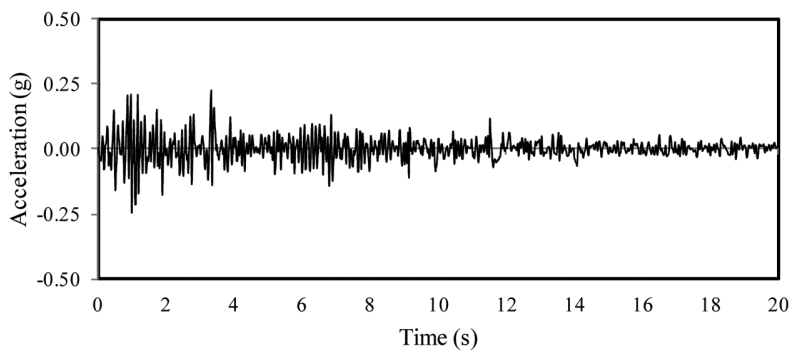

(c)

Fig. 6 Scaled acceleration time-history of El Centro ground motion: (a) Longitudinal component, (b) transverse component and (c) vertical component

Rayleigh damping is used in the direct step-by-step integration method so that the stiffness proportional damping equivalent to $5 \%$ of the critical damping is assumed as the structural damping and for the convective and impulsive components of the contained liquid, $0.5 \%$ and $5 \%$ of the critical damping is applied, respectively.

\section{Results and discussion}

\subsection{Intensifying time-stepped loading}

In this section, results obtained from exciting the tank-liquid system in longitudinal direction using the artificial dynamic load are considered and compared with those obtained from ABAQUS 6.5.1. Clearly, the similar finite element model, boundary conditions and material properties are provided in ABAQUS. It should be mentioned that this commercial software neglects the sloshing effects in small liquid domains such as those contained in tanks. 
Fig. 7 shows the displacement time-history of the tank crest point in the horizontal direction, when there is not any convective term. Comparing the results shown in this figure, there is acceptable consistency between the two methods neglecting sloshing effects. However, ABAQUS generates lower results in comparison with the proposed method. In addition, high frequency vibrations of the walls are damped faster. Fig. 8 shows the displacement time-history in the horizontal direction for the empty and full tanks with and without considering convective term effects. As can be seen, including the impulsive component lead to raise the response of the empty tank. However, the convective term changes the trend of the response drastically so that a relatively long period fluctuation related to the surface sloshing can be observed.

Fig. 9 represents the time-history of the base shears and base moments resulted from the convective and impulsive terms of the liquid domain when the container is full. As can be seen, the convective component affects considerably the base shear and base moment and includes a long period vibration due to vibrating the nature of this component. Based on the results, the generated shear and moment at the base of the tank have greater value for the convective term when the acceleration amplitude is $0.2 \mathrm{~g}$; they have almost the same value when the acceleration $0.4 \mathrm{~g}$; and finally, the impulsive term leads to the higher values for higher accelerations.

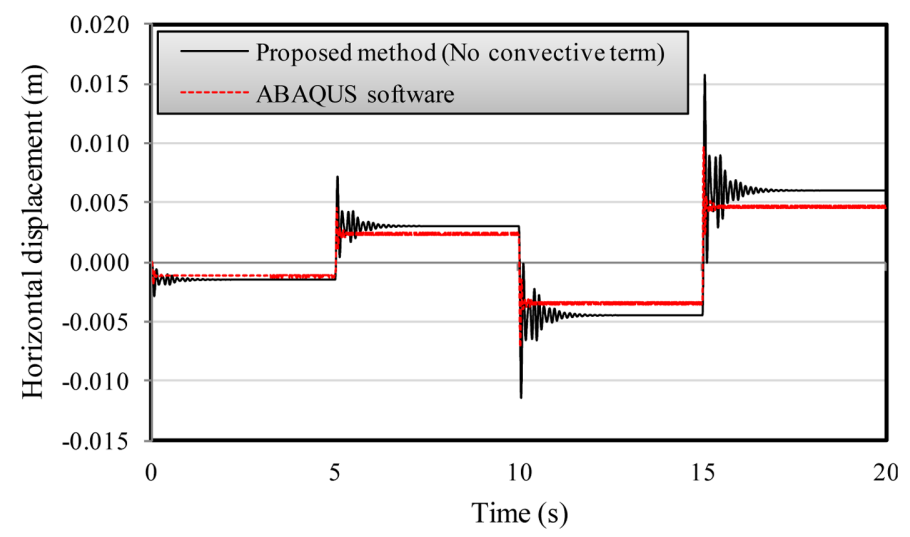

Fig. 7 Comparison of horizontal displacement in ABAQUS software and proposed method without convective term effect

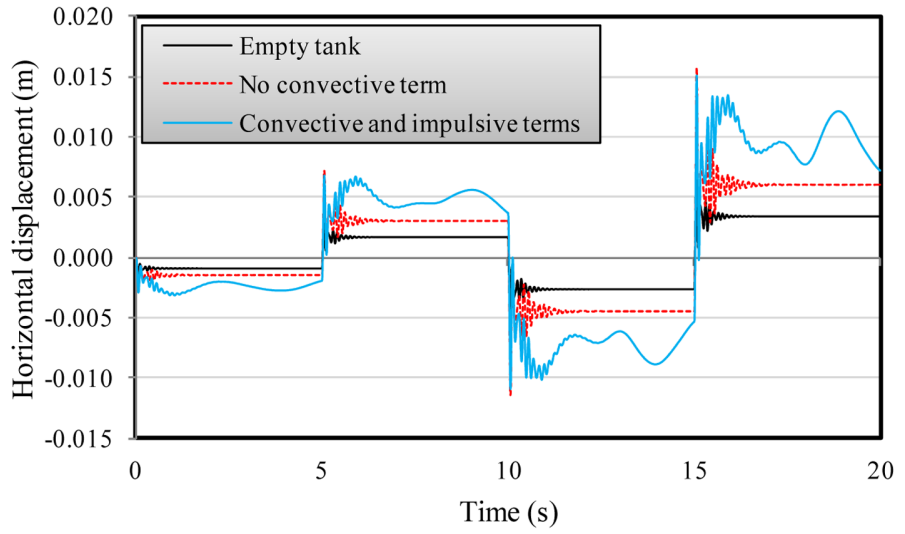

Fig. 8 Time-history of the horizontal displacement resulted from the proposed method 


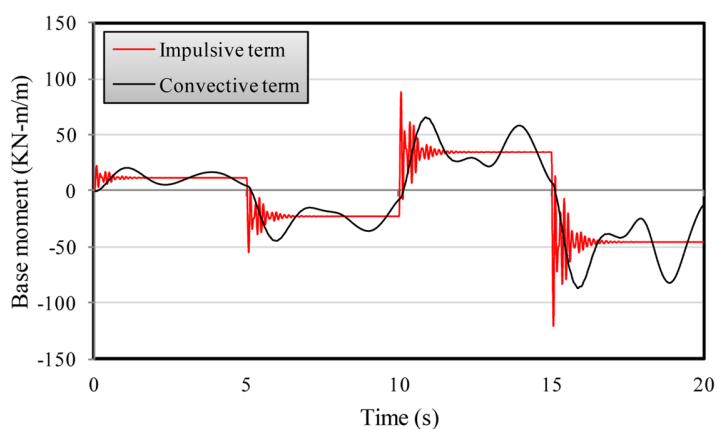

(a)

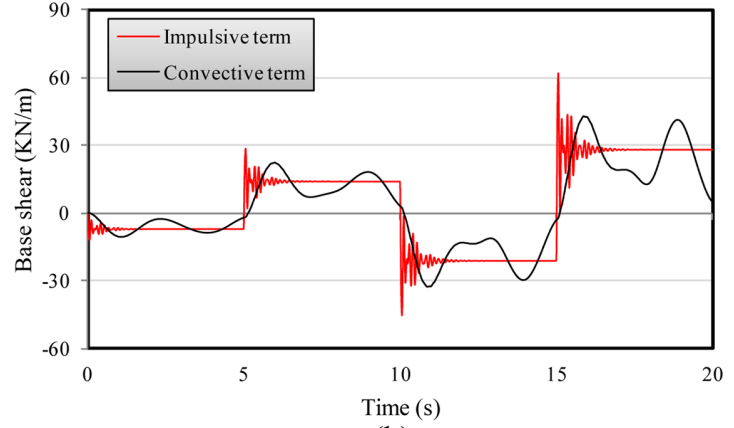

(b)

Fig. 9 Time-history of the (a) base moment and (b) base shear originated from the convective and impulsive terms

\subsection{Earthquake ground motion loading}

In this section, the results of dynamic analysis of the system excited using the scaled El-Centro ground motion are considered. Four loads combinations were investigated in the present study; in the first one only longitudinal component was applied to the system and the responses were extracted in the same direction (Wall No. 1); in the second one horizontal transverse component of the ground motion was applied and results were interpreted for wall No. 2; in the third one vertical component was applied to the system and finally in the fourth load combination all the three components were applied to the system, simultaneously.

\subsubsection{Excitation using the longitudinal component}

Fig. 10 shows the time-history of the horizontal displacement at top of the tank wall when excited using the longitudinal component of the earthquake record. ABAQUS software provides the results, which are about $20 \%$ less than the proposed method. The same plots for the base shear and base moment are shown in Fig. 11. As can be seen, the convective term forms significant portion of the response.

Fig. 12(a) shows the time-history of the free surface sloshing in the applied loading condition.

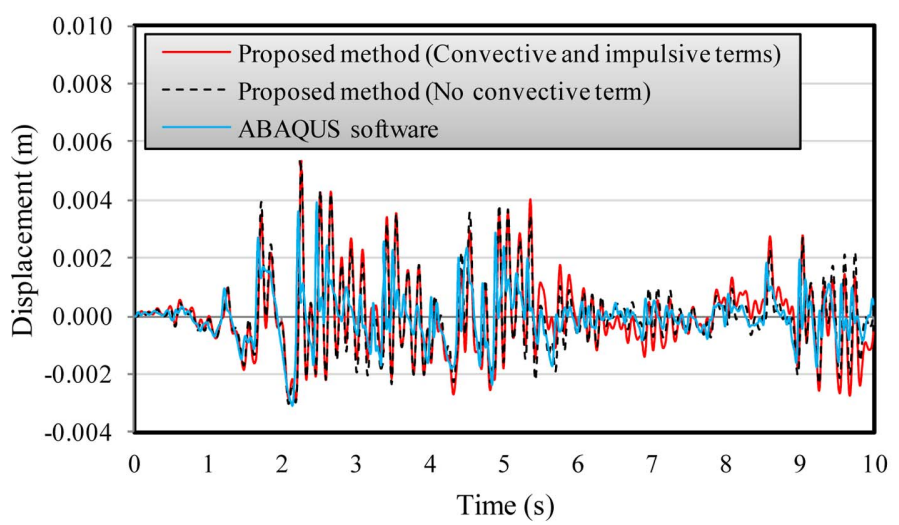

Fig. 10 Time-history of the displacement in the horizontal direction 


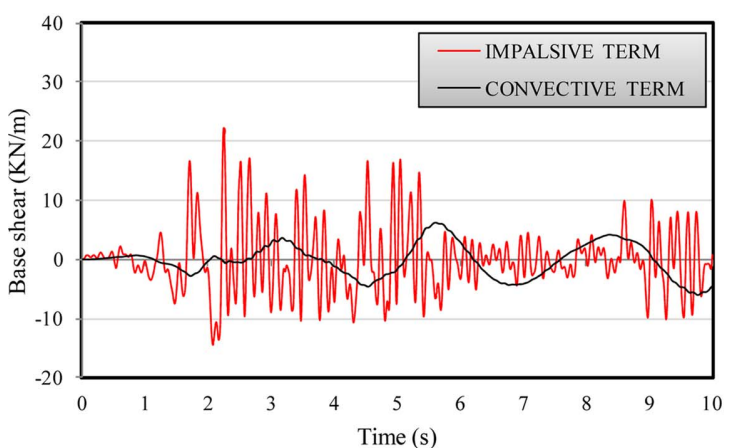

(a)

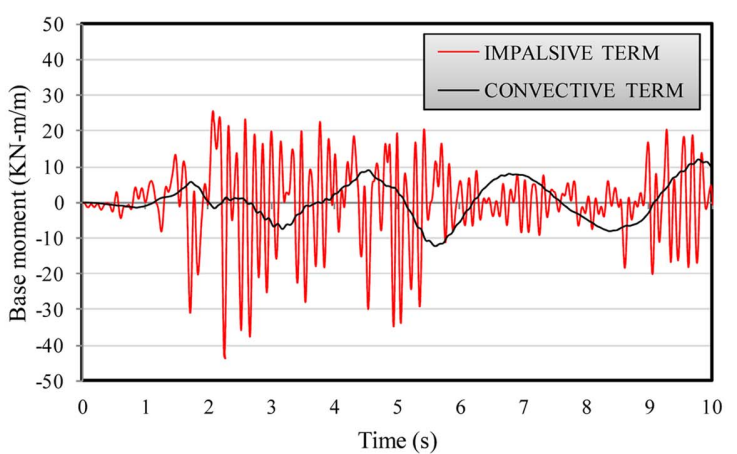

(b)

Fig. 11 Time-history of (a) the base moment and (b) the base shear originated from the convective and impulsive terms

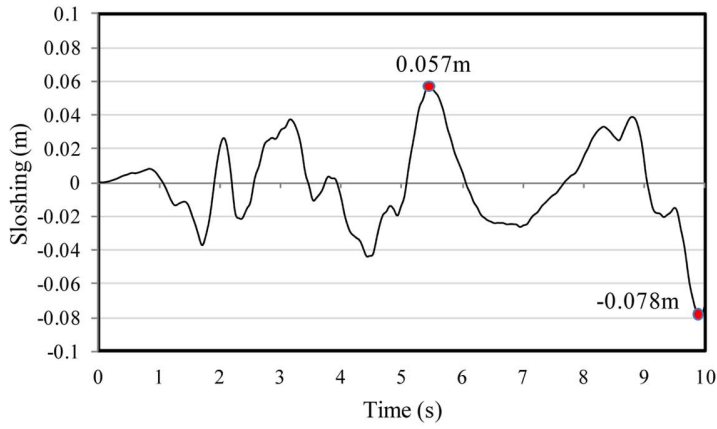

(a)

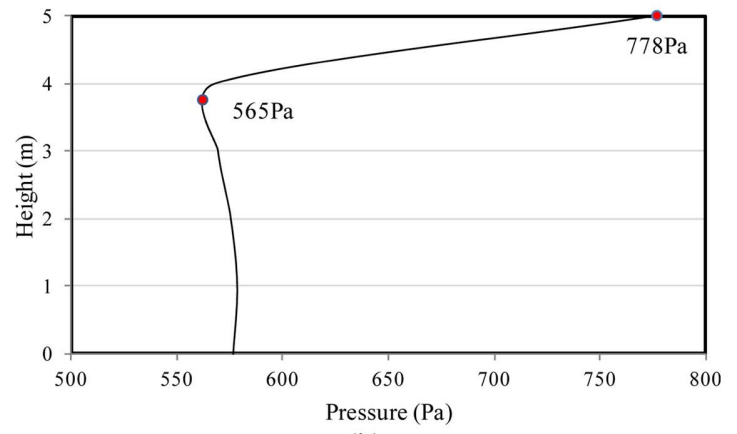

(b)

Fig. 12 (a) Time-history of the free surface sloshing and (b) distribution of the hydrodynamic pressure along the height of wall No. 1 at the time corresponding to the maximum surface sloshing

Based on this figure, free surface of the liquid experiences rising up to $57 \mathrm{~mm}$ and falling about $78 \mathrm{~mm}$. Fig. 12(b) shows the hydrodynamic pressure distribution along the height of the wall No. 1 corresponding to the time when the maximum surface sloshing occurs. Table 2 summarizes the responses of the tank-liquid system at time $t=2.25 \mathrm{~s}$ at which all the responses reach to their maximum values. Based on this table, including the convective term leads to decrease in the horizontal displacement of the tank crest about $1.8 \%$, decreasing the tank total base moment about $1.6 \%$ and it has no effect on the total base shear.

\subsubsection{Excitation using transverse component}

Fig. 13 shows the crest time history of the tank experienced by the long wall in the exciting direction. Due to smaller dimension for fluctuation of the fluid in this condition, the effect of convective term is much clear than previous one. Fig. 14 shows time-history of the free surface sloshing and the corresponding hydrodynamic pressure distribution at the time of maximum sloshing on wall No. 2, respectively. Based on this figure, free surface of the fluid experiences rising up to $110 \mathrm{~mm}$ and falling about $91 \mathrm{~mm}$. Like as shown in the previous section, the distribution of hydrodynamic pressure is nonlinear along the height of the tank wall and it reaches to $1080 \mathrm{~Pa}$ at the crest of the tank and its minimum value is $859 \mathrm{~Pa}$ near the crest. 
Table 2. Summarized results of the system excited using the longitudinal component of the ground motion

\begin{tabular}{lrcc}
\hline \hline \multirow{2}{*}{ Results } & \multirow{2}{*}{ Empty tank } & \multicolumn{2}{c}{ Full tank } \\
\cline { 3 - 4 } & & No convective Term & Convective and impulsive terms \\
\hline Horizontal displacement $(\mathrm{mm})$ & $2.7 /-1.8^{*}$ & $5.4 /-3.0$ & $5.3 /-2.9$ \\
Total base moment $(\mathrm{KN}-\mathrm{m} / \mathrm{m})$ & $19 /-24$ & $40 /-62$ & $38 /-61$ \\
Total base shear $(\mathrm{KN} / \mathrm{m})$ & $10 /-10$ & $30 /-22$ & $30 /-20$ \\
Sloshing height $(\mathrm{mm})$ & & & $57 /-78$ \\
Impulsive base shear $(\mathrm{KN} / \mathrm{m})$ & & $22.1 /-13.9$ \\
Convective base shear $(\mathrm{KN} / \mathrm{m})$ & & $6 /-6$ \\
Impulsive base moment $(\mathrm{KN}-\mathrm{m} / \mathrm{m})$ & & $26 /-44$ \\
Convective base moment $(\mathrm{KN}-\mathrm{m} / \mathrm{m})$ & & $12 /-12$ \\
\hline
\end{tabular}

${ }^{*}$ The (-) sign indicates the response of system in opposite side of axis

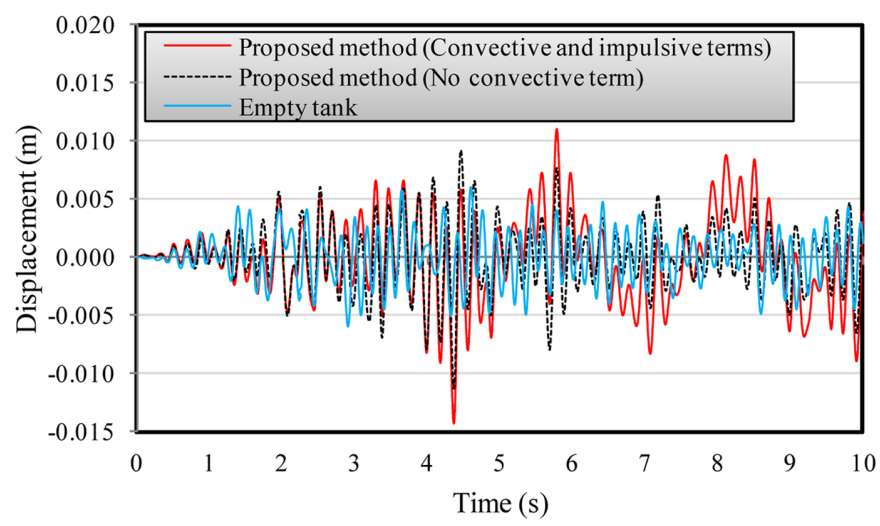

Fig. 13 Time-history of the displacement in the horizontal direction (parallel to the short wall)

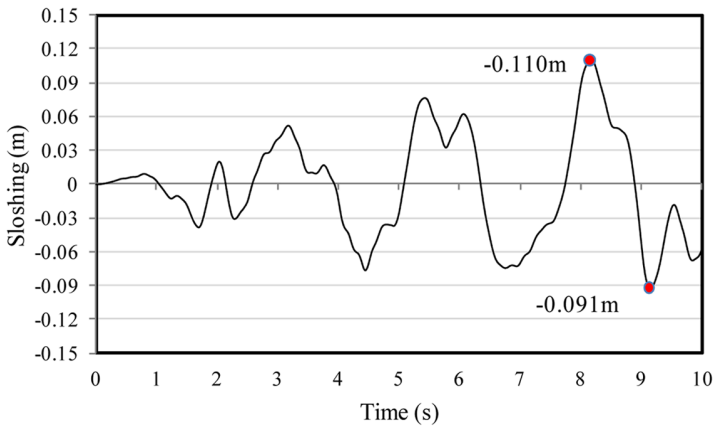

(a)

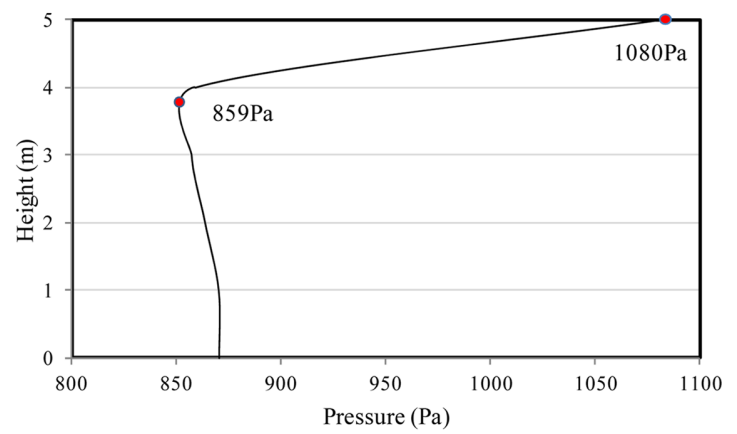

(b)

Fig. 14 (a) Time-history of the free surface sloshing and (b) distribution of the hydrodynamic pressure along the height of wall No. 2 at the time of maximum surface sloshing

Table 3 summarize the responses of the tank-liquid system at time $t=4.355 \mathrm{~s}$ which all the responses reach their maximum values. Including the convective term leads to increasing the horizontal displacement of the tank crest point about $27.3 \%$. In addition, the increase in the base moment and 
Table 3. Summarized results of the system response excited using the transverse component

\begin{tabular}{lccc}
\hline \multirow{2}{*}{ Results } & \multirow{2}{*}{ Empty tank } & \multicolumn{2}{c}{ Full tank } \\
\cline { 3 - 4 } & & No convective term & Convective and impulsive terms \\
\hline Horizontal displacement $(\mathrm{mm})$ & $6.0 /-6.0^{*}$ & $9.0 /-11.0$ & $10.95 /-14.02$ \\
Total base moment $(\mathrm{KN}-\mathrm{m} / \mathrm{m})$ & $42 /-42$ & $76 /-84$ & $86 /-110$ \\
Total base shear $(\mathrm{KN} / \mathrm{m})$ & $10 /-10$ & $25 /-25$ & $26 /-32$ \\
Sloshing height $(\mathrm{mm})$ & & & $110 /-91$ \\
Impulsive base shear $(\mathrm{KN} / \mathrm{m})$ & & & $28 /-22$ \\
Convective base shear $(\mathrm{KN} / \mathrm{m})$ & & $13 /-13$ \\
Impulsive base moment $(\mathrm{KN}-\mathrm{m} / \mathrm{m})$ & & $90 /-71$ \\
Convective base moment $(\mathrm{KN}-\mathrm{m} / \mathrm{m})$ & & $37 /-37$ \\
\hline
\end{tabular}

${ }^{*}$ The (-) sign indicates the response of system in opposite side of axis

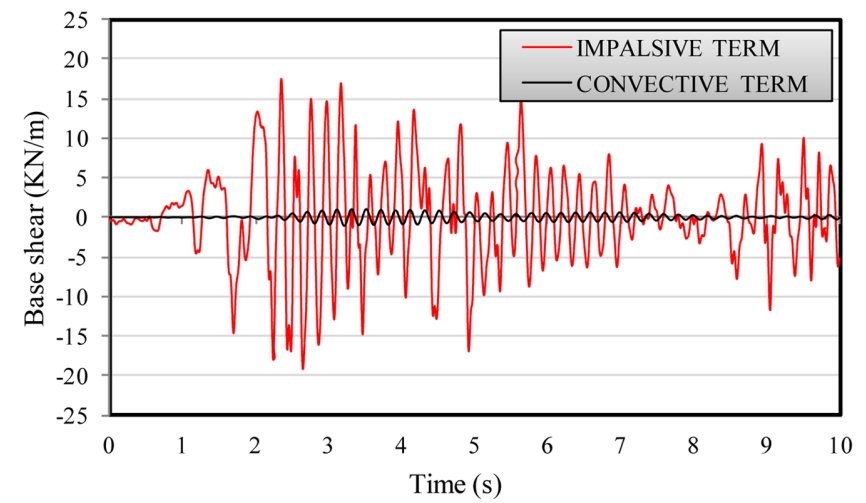

(a)

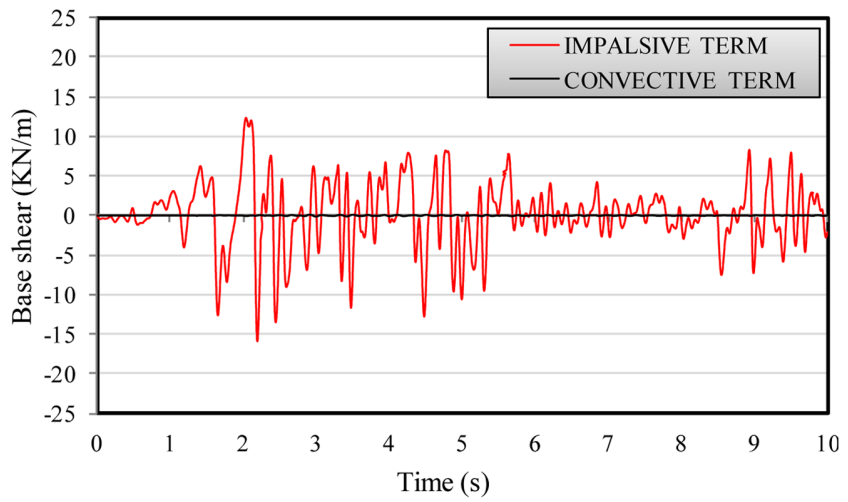

(b)

Fig. 15 Time-history of the base shear using the proposed method originated from the convective and impulsive terms (a) Long wall, No. 2 and (b) short wall, No. 1

base shear are about $30.9 \%$ and $28 \%$, respectively. Therefore, unlike the results of the previous condition, including the convective term leads to increase in all major responses of the tank. 
Table 4. Summarized results of the system response excited using vertical component

\begin{tabular}{|c|c|c|c|c|}
\hline & \multirow{2}{*}{ Results } & \multirow{2}{*}{$\begin{array}{c}\text { Empty } \\
\text { tank }\end{array}$} & \multicolumn{2}{|r|}{ Full tank } \\
\hline & & & No convective term & Convective and impulsive terms \\
\hline \multirow{8}{*}{$\begin{array}{l}\text { Wall } \\
\text { No.1 }\end{array}$} & Horizontal displacement (mm) & $\sim 0.0$ & $\sim 0.0$ & $\sim 0.0$ \\
\hline & Total base moment $(\mathrm{KN}-\mathrm{m} / \mathrm{m})$ & $\sim 0.0$ & $19 /-29$ & $19 /-29$ \\
\hline & Total base shear $(\mathrm{KN} / \mathrm{m})$ & $\sim 0.0$ & $12 /-16$ & $12 /-16$ \\
\hline & Sloshing height $(\mathrm{mm})$ & & & $\sim 0.0$ \\
\hline & Impulsive base shear (KN/m) & & & $12 /-16$ \\
\hline & Convective base shear (KN/m) & & & $\sim 0.0$ \\
\hline & Impulsive base moment (KN-m/m) & & & $19 /-29$ \\
\hline & Convective base moment $(\mathrm{KN}-\mathrm{m} / \mathrm{m})$ & & & $0.5 /-0.2$ \\
\hline \multirow{8}{*}{$\begin{array}{l}\text { Wall } \\
\text { No.2 }\end{array}$} & Horizontal displacement (mm) & $\sim 0.0$ & $\sim 0.0$ & $\sim 0.0$ \\
\hline & Total base moment $(\mathrm{KN}-\mathrm{m} / \mathrm{m})$ & $\sim 0.0$ & $57 /-60$ & $57 /-60$ \\
\hline & Total base shear $(\mathrm{KN} / \mathrm{m})$ & $\sim 0.0$ & $18 /-20$ & $18 /-20$ \\
\hline & Sloshing height $(\mathrm{mm})$ & & & $\sim 0.0$ \\
\hline & Impulsive base shear (KN/m) & & & $17 /-19$ \\
\hline & Convective base shear $(\mathrm{KN} / \mathrm{m})$ & & & $0.9 /-1.0$ \\
\hline & Impulsive base moment $(\mathrm{KN}-\mathrm{m} / \mathrm{m})$ & & & $57 /-61$ \\
\hline & Convective base moment $(\mathrm{KN}-\mathrm{m} / \mathrm{m})$ & & & $3.1 /-2.2$ \\
\hline
\end{tabular}

${ }^{*}$ The (-) sign indicates the response of system in opposite side of axis

\subsubsection{Excitation using vertical component}

The resulted displacements (especially for the case without convective term) are very small so they can be neglected. Fig. 15 represents time-history of the base shear in both the long and short walls. As it is clear, the convective term has little or no effect on the generated base shear in the walls. However, its value in wall No. 2 is greater than that in wall No. 1. Table 4 summarizes the response of the system. As mentioned before, in the case with vertical excitation the convective term almost has no effect on the generated responses.

\subsubsection{Excitation using three-component ground motion}

Fig. 16 shows time-history of the displacement at the middle crest of walls No. 1 and 2, respectively for the two cases of full and empty tank. In both directions, convective part has a great effect on the responses. The effect of convective component on wall No. 2 (long wall) is more than wall No. 1. During the seismic action, the displacements at some locations show larger values for the cases excluding the convective component in comparison with the cases including the two components of the contained liquid. The main reason is that the convective and impulsive forces are acting in different phases at the considered times and so the resultant force may be smaller. Moreover, Fig. 17 represents time-history of the base shear experienced by the walls. As it's clear, the shear force resulted from the impulsive term is directly related to the ground motion itself, so the value of the pertinent base shear in the longitudinal direction (perpendicular to the wall No. 1) is more than the other, while the convective base shear depends on the surface sloshing; so its value on wall No. 2 is more than the others. Total shear is resultant of the convective and impulsive pertinent shears and can varies based on the frequency content of the ground motion. 


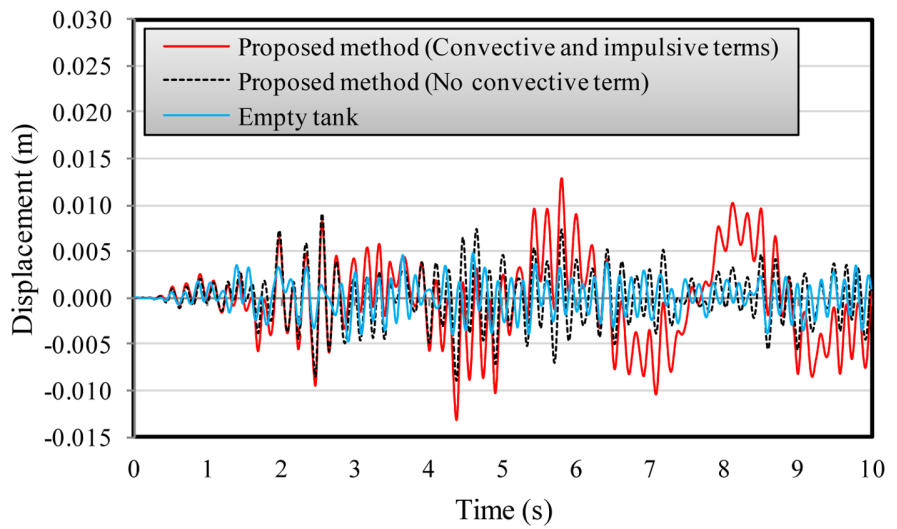

(a)

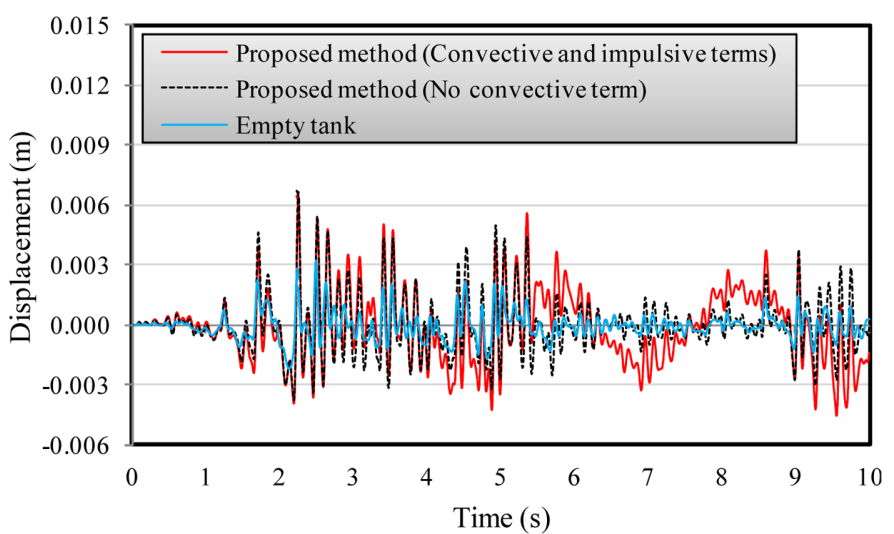

(b)

Fig. 16 Time-history of the horizontal displacement originated from the convective and impulsive terms (a) Long wall, No. 2 and (b) short wall, No. 1

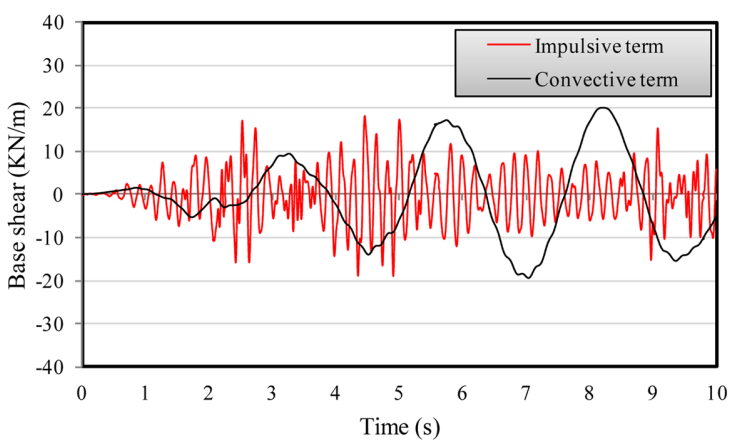

(a)

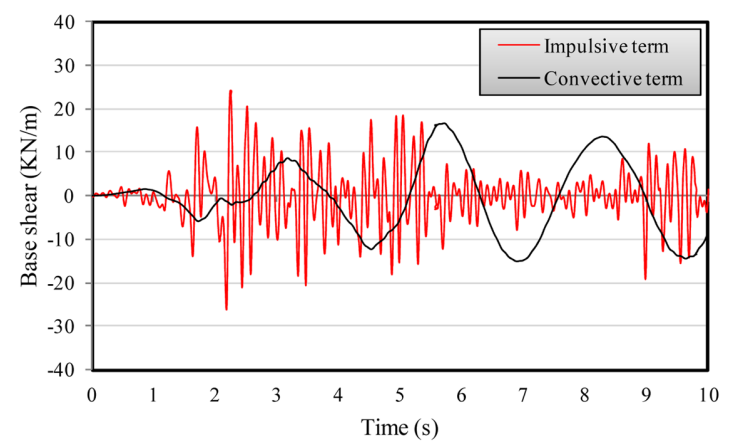

(b)

Fig. 17 Time-history of the base shear originated from the convective and impulsive terms (a) Long wall, No. 2 and (b) Short wall, No. 1

Fig. 18 represents time-history of the free surface sloshing on both walls resulted from excitation of the system using the three-component ground motion. As expected, the resulted sloshing on wall 


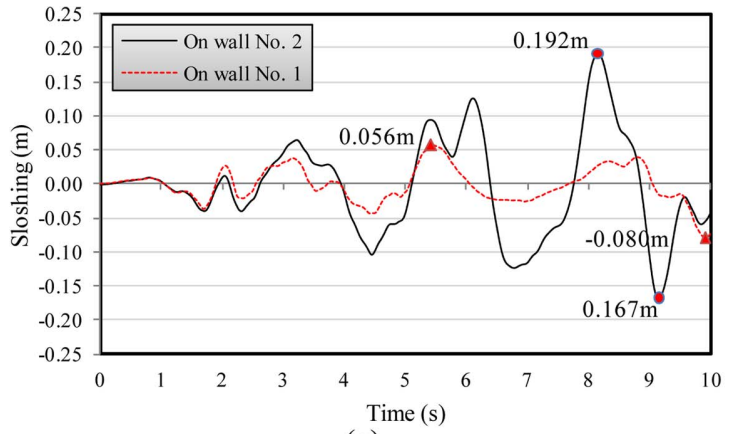

(a)

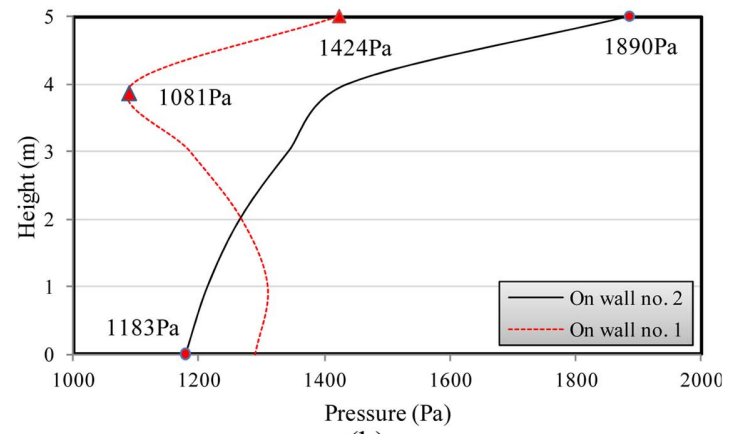

(b)

Fig. 18 (a) Time-history of free surface sloshing and (b) distribution of hydrodynamic pressure along the height of tank walls No. 1 and 2 at the time of maximum surface sloshing

Table 5. Summarized results of three-directional analysis of system using three-component

\begin{tabular}{|c|c|c|c|c|}
\hline & \multirow{2}{*}{ Results } & \multirow{2}{*}{$\begin{array}{c}\text { Empty } \\
\text { tank }\end{array}$} & \multicolumn{2}{|r|}{ Full tank } \\
\hline & & & \multicolumn{2}{|c|}{ No convective term Convective and impulsive terms } \\
\hline & Horizontal displacement (mm) & $2.7 /-1.8$ & $6.8 /-3.8$ & $6.5 /-4.5$ \\
\hline & Total base moment (KN-m/m) & $19 /-24$ & $55 /-70$ & $62 /-67$ \\
\hline & Total base shear $(\mathrm{KN} / \mathrm{m})$ & $9 /-9$ & $32 /-32$ & $30 /-34$ \\
\hline Wall & Sloshing height (mm) & & & $56 /-80$ \\
\hline \multirow[t]{7}{*}{ No.1 } & Impulsive base shear $(\mathrm{KN} / \mathrm{m})$ & & & $24 /-26$ \\
\hline & Convective base shear (KN/m) & & & $17 /-15$ \\
\hline & Impulsive base moment (KN-m/m) & & & $44 /-53$ \\
\hline & Convective base moment $(\mathrm{KN}-\mathrm{m} / \mathrm{m})$ & & & $28 /-32$ \\
\hline & Horizontal displacement (mm) & $6 /-6$ & $9 /-9$ & $-13 / 13$ \\
\hline & Total base moment $(\mathrm{KN}-\mathrm{m} / \mathrm{m})$ & $42 /-41$ & $63 /-69$ & $102 /-105$ \\
\hline & Total base shear $(\mathrm{KN} / \mathrm{m})$ & $11 /-11$ & $20 /-24$ & $31 /-35$ \\
\hline Wall & Sloshing height (mm) & & & $192 /-167$ \\
\hline \multirow[t]{4}{*}{ No.2 } & Impulsive base shear (KN/m) & & & $18 /-19$ \\
\hline & Convective base shear (KN/m) & & & $20 /-19$ \\
\hline & Impulsive base moment $(\mathrm{KN}-\mathrm{m} / \mathrm{m})$ & & & $65 /-60$ \\
\hline & Convective base moment $(\mathrm{KN}-\mathrm{m} / \mathrm{m})$ & & & $61 /-57$ \\
\hline
\end{tabular}

${ }^{*}$ The (-) sign indicates the response of system in opposite side of axis

No. 2 is more than wall No.1. Also, for the first two second of the seismic excitation in which the motion of the liquid contained in the tank has uniform shape, the resulted sloshing on both walls has the same rate. After $t=2.0 \mathrm{~s}$ due to vibration of walls; increasing level of dynamic load and interaction wave propagation in the three perpendicular directions; different sloshing is generated in the two directions. In addition, this figure shows the hydrodynamic pressure distribution along the walls at the time of maximum sloshing. As it is clear, due to various vibrations of the small and long wall; the resulted hydrodynamic pressure on wall No. 2 is different from wall No. 1. Anyway, the threecomponent ground motion leads to the higher hydrodynamic pressure on wall No. 2. Table 5 
summarizes the responses of the tank-liquid system excited using the three-component ground motion. Almost all responses on the wall No. 2 are higher than those on the wall No. 1. The total base moment on wall No. 2 is about $57 \%$ more than that applied on the wall No. 1 ; however the value of the base shear is $3 \%$ higher.

\section{Conclusions}

In the present paper, the staggered displacement method was utilized to consider the seismic behaviour of liquid storage tanks in 3D space. In the proposed method, liquid was modelled using rigorous finite element technique and damping effects due to impulsive and convective terms of the contained liquid was taken into account appropriately. The finite element model of a tank-liquid system was provided as case study while its base was considered to be rigid. An artificial dynamic load as well as a real ground motion was selected to analyse the system. In addition ABAQUS commercial software was used for verification of the results of the proposed method without considering convective term of the liquid. The results show good consistency between ABAQUS and the proposed method, while ABAQUS leads to lower results. The main reason is the different techniques used by ABAQUS for applying the dynamic loads on the system and the different utilized solver. It is noteworthy that the accuracy and applicability of the proposed method in analysing the coupled systems were verified due to several works presented by the second author and his co-workers in the field of dam engineering.

Four load combinations were considered for excitation of the system subjected to the real ground motion. In the first three analyses, the three components of the selected earthquake record were applied to the system individually and in the fourth case all the three components were applied simultaneously. The results of the tank-liquid system with/without convective term were investigated. It was concluded that combination of all ground motion components leads to higher responses on both walls of the tank in comparison with the cases applying them individually. Generally, the resulted responses on the longer wall of the tank are more than those on the shorter one especially for the crest displacement; the sloshing height and the generated base moment. In addition, in horizontal excitation of the system, the convective term forms the important part of the generated results while in the vertical excitation it has almost no effect on responses.

Generally, including the convective term may leads to increase or decrease of the responses due to different phases of the convective and impulsive components in the liquid domain.

\section{References}

ABAQUS 6.5.1. (2007), Analysis User's Manual.

Bayraktar, A., Sevim, B., Can Altunl lk, A. and Türker, T. (2010), "Effect of the model updating on the earthquake behaviour of steel storage tanks", J. Constr. Steel Res., 66(3), 462-469.

Berahman, F. and Behnamfar, F. (2009), "Probabilistic seismic demand model and fragility estimates for critical failure modes of un-anchored steel storage tanks in petroleum complexes", Probabilist. Eng. Mech., 24(4), 527-536.

Chen, J.Z. and Kianoush, M.R. (2009), "Generalized SDOF system for seismic analysis of concrete rectangular liquid storage tanks", Eng. Struct., 31(10), 2426-2435.

Cho, J.R. and Lee, H.W. (2004), "Numerical study on liquid sloshing in baffled tank by nonlinear finite element 
method", Comput. Method. Appl. M., 193(23), 2581-2598.

Dutta, S.C., Jain, S.K. and Murty, C.V.R. (2000), "Assessing the seismic torsional vulnerability of elevated tanks with RC frame-type staging", Soil Dyn. Earthq. Eng., 19(3), 183-197.

Estekanchi, H.E. and Alembagheri, M. (2012), "Seismic analysis of steel liquid storage tanks by Endurance Time method", Thin Wall. Struct., 50(1), 14-23.

Firouz-Abadi, R.D., Ghasemi, M. and Haddadpour, H. (2011), "A modal approach to second-order analysis of sloshing using boundary element method", Ocean Eng., 38(1), 11-21.

Firouz-Abadi, R.D., Haddadpour, H. and Ghasemi, M. (2009), "Reduced order modelling of liquid sloshing in 3D tanks using boundary element method", Eng. Anal. Bound. Elem., 33(6), 750-761.

Frandsen, J.B. (2004), "Sloshing motions in excited tanks", J.Comput. Phys., 196(1), 53-87.

Ghaemian, M., Kianoush, M.R. and Mirzabozorg, H. (2005), "Time domain dynamic analysis of rectangular liquid containers in three-dimensional space", European Earthq. Eng., 2, 3-9.

Hamdan, F.H. (2000), "Seismic behaviour of cylindrical steel liquid storage tanks", J. Constr. Steel Res., 53(3), 307-333.

Hernández-Barrios, H., Heredia-Zavoni, E. and Aldama-Rodríguez, A.A. (2007), "Nonlinear sloshing response of cylindrical tanks subjected to earthquake ground motion", Eng. Struct., 29(12), 3364-3376.

Huang, S., Duan, W. and Zhu, X. (2010), "Time-domain simulation of tank sloshing pressure and experimental validation", J. Hydro.- Ser. B, 22(5), 556-563.

Kianoush, M.R. and Ghaemmaghami, A.R. (2011), "The effect of earthquake frequency content on the seismic behaviour of concrete rectangular liquid tanks using the finite element method incorporating soil-structure interaction", Eng. Struct., 33(7), 2186-2200.

Kianoush, M.R. and Chen, J.Z. (2006), "Effect of vertical acceleration on response of concrete rectangular liquid storage tanks", Eng. Struct., 28(5), 704-715.

Kianoush, M.R., Mirzabozorg, H. and Ghaemian, M. (2006), "Dynamic analysis of rectangular liquid containers in three-dimensional space", Canadian J.Civil Eng., 33, 501-507.

Livaoglu, R. (2008), "Investigation of seismic behaviour of fluid-rectangular tank-soil/foundation systems in frequency domain", Soil Dynam. Earthq. Eng., 28(2), 132-146.

Livaoglu, R. and Dogangun, A. (2007), "Effect of foundation embedment on seismic behaviour of elevated tanks considering fluid-structure-soil interaction", Soil Dynam. Earthq. Eng., 27(9), 855-863.

Ming, P. and Duan, W. (2010), "Numerical simulation of sloshing in rectangular tank with VOF based on unstructured grids", J. Hydro.- Ser. B, 22(6), 856-864.

Mirzabozorg H., Khaloo A.R. and Ghaemian, M. (2003), "Staggered solution scheme for three dimensional analysis of dam-reservoir interaction", Dam Eng., 14(3), 147-164.

Mirzabozorg, H. and Ghaemian, M. (2005), "Nonlinear behavior of mass concrete in three-dimensional problems using smeared crack approach", Earthq. Eng. Struct. D., 34, 247-269.

Mirzabozorg, H., Kianoush, R. and Jalalzadeh, B. (2009), "Damage mechanics approach and modeling nonuniform cracking within finite elements for safety evaluation of concrete dams in 3D space", Struct. Eng. Mech., 33(1), 91-46.

Moslemi, M., Kianoush, M.R. and Pogorzelski, W. (2011), "Seismic response of liquid-filled elevated tanks", Eng. Struct., 33(6), 2074-2084.

Nasar, T., Sannasiraj, S.A. and Sundar, V. (2008), "Experimental study of liquid sloshing dynamics in a barge carrying tank", Fluid Dynam. Res., 40(6), 427-458.

Nachtigall, I., Gebbeken, N. and Urrutia-Galicia, J.L. (2003), "On the analysis of vertical circular cylindrical tanks under earthquake excitation at its base", Eng. Struct., 25(2), 201-213.

Nourali-Ahari, M., Eshghi, S. and Ghafory-Ashtiany, M. (2009), "The tapered beam model for bottom plate uplift analysis of unanchored cylindrical steel storage tanks", Eng. Struct., 31(3), 623-632.

Serdar Celebi, M. and Akyildiz, h. (2002), "Nonlinear modelling of liquid sloshing in a moving rectangular tank", Ocean Eng., 29(12), 1527-1553.

Shrimali, M.K. and Jangid, R.S. (2003), "Earthquake response of isolated elevated liquid storage steel tanks", $J$. Constr. Steel Res., 59(10), 1267-1288.

Sweedan, A.M.I. (2009), "Equivalent mechanical model for seismic forces in combined tanks subjected to vertical earthquake excitation", Thin Wall. Struct., 47(8-9), 942-952. 
Virella, J.C., Godoy, L.A. and Suárez, L.E. (2006), "Dynamic buckling of anchored steel tanks subjected to horizontal earthquake excitation”, J. Constr. Steel Res., 62(6), 521-531.

$\mathrm{Wu}, \mathrm{C}$. and Chen, B. (2009), "Sloshing waves and resonance modes of fluid in a 3D tank by a time-independent finite difference method", Ocean Eng., 36(6-7), 500-510. 